\title{
Oorsig van faseveranderingsmateriaal vir sub-zero temperatuurtoepassings in verkoelingsvervoer
}

\begin{abstract}
Outeurs:
Casey Ndanduleni,

Zhongjie Huan

Affiliasie:

Departement van Meganiese Ingenieurswese, Megatronika en Bedryfsontwerp, Tshwane Universiteit van Tegnologie, Pretoria, Suid Afrika

Korresponderende outeur: Prof Zhongjie Huan E-pos: huanz@tut.ac.za

\section{Ontvang: $\quad 04 / 12 / 18$ \\ Aanvaar: $\quad 28 / 05 / 19$ \\ Gepublisser: 09/09/19 \\ Hoe om hierdie artikel aan te haal: \\ Casey Ndanduleni, Zhongjie Huan, Oorsig van faseveranderingsmateriaal vir sub-zero temperatuur- toepassings in ver- koelingsvervoer, Suid- Afrikaanse Tydskrif vir Natuurwetenskap en Tegnologie 38(1) (2019). https://doi.org/10.36303/ SATNT.2019.38.1.715}

Datums:
\end{abstract}

An English copy of this paper is available online at http://www.satnt.ac.za/ index.php/satnt/article/ view/715

Kopiereg:

(c) 2019. Authors.

Licensee: Die SuidAfrikaanse Akademie vir Wetenskap en Kuns. Hierdie werk is onder die Creative Commons Attribution License gelisensieer.
Hierdie artikel bied 'n oorsig van die tradisionele gebruik van faseveranderingsmateriaal (FVM) in verkoelingsvervoer. Die meerderheid faseveranderingsmateriale in bouwerk en konstruksie word vir ruimtelike verwarming en verkoeling, kweekhuis-verhitting, kook met sonkrag, en die berging van son-energie vir waterverhitting gebruik. Daar is egter ' $n$ merkbare afwesigheid van literatuur oor die aanwending van faseveranderingsmateriaal vir gebruik om bevrore voedselprodukte te bewaar. Hierdie oorsig fokus op latente hittebewarings (LHB) materiale se gebruik in padvervoer by 'n lae temperatuur (sub-zero), en van die voordele vir die verkoeling van bederfbare voedsel oor kort- en lang-afstande. Die voordele van die gebruik van latente hitte-bewaringsmateriaal, eerder as ' $n$ konvensionele meganiese verdampings-kompressiesisteem, word ondersoek met die klem op die omgewingsimpak en moontlike langtermyn nadele. Die studie fokus ook op die noodsaaklikheid om nuwe faseveranderingsmateriaal met hoë termiese siklusse en minimale degradering te ondersoek, ten einde die suksesvolle gebruik in verkoelingsvervoer oor die langtermyn te verseker. Kriteria vir die seleksie van toepaslike faseveranderingsmateriaal word opgesom, en 'n klassifikasie van faseveranderingsmateriaal, gebaseer op smelttemperature en latente warmte, word getabuleer. Faseveranderingsmateriaal en die oordrageienskappe daarvan is ontleed ten einde die eienskappe van faseveranderingsmateriaal op te som, en die akkuraatheid van elke navorsingstegniek word beoordeel op grond van soortgelyke studies wat deur ander navorsers publiseer is. Die faseveranderingsmateriaal wat in verkoelingsvervoer gebruik word, is empiries ontleed, en termiese-fisiese kriteria wat noodsaaklik is vir verskillende toepassings is ook onder die vergrootglas geplaas.

Sleutelwoorde: Eutekties, globale verhittingspotensiaal, latente smeltwarmte, faseveranderingsmateriaal, termiese energiebewaring.

Review on phase change materials for sub-zero temperature application in transport refrigeration: This paper reviews the use of phase change materials (PCMs) in road transport refrigeration. The use of thermal energy storage systems in transport refrigeration focusing particularly on PCMs that have been used in recent years is reviewed. The majority of PCMs are used in building applications for space heating and cooling, greenhouse heating applications, solar cookers, and storage of solar energy for water heating. However, there is minimal focus in the literature on their use in road transport refrigeration in low temperature (sub-zero) application for maintaining frozen foodstuff (products). The focus of this work is on latent heat storage (LHS) materials used in road transport refrigeration and their benefits in the refrigeration of perishable foodstuffs for short- and long-distance transportation. The benefits of using LHS materials over a conventional mechanical vapour compression system are explored with reference to the environmental impact and their disadvantages in the long term. This paper also focuses on the need to develop new PCMs with high thermal cycles and minimal degradation to ensure their successful use in the transport refrigeration industry. Criteria for selecting suitable PCMs for different applications were summarised, and classification of PCMs based on their melting temperature and latent heat were tabulated. Heat transfer materials for increasing PCM performance were analysed as well as the effect of container material corrosion on PCM stability. The different thermal techniques used for determining the properties of PCMs were summarised, and the accuracy of each technique was explored based on similar research work by other researchers. The PCMs that have been used in transport refrigeration as well as the thermo-physical criteria that are needed for different applications were analysed.

Keywords: eutectic, global warming potential, latent heat of fusion, phase change material, thermal energy storage 


\section{Inleiding}

As gevolg van bevolkingstoename is daar tans ' $\mathrm{n}$ groter behoefte onder verbruikers vir meer bevrore en verkoelde voedselprodukte (Fioretti et al., 2016). Verkoeling is dus noodsaaklik ten einde die kwaliteit, veiligheid en verlenging van die raklewe van temperatuur-sensitiewe voedselsoorte te verbeter. Die oorweging van verkoelingsvervoer van bederfbare voedsel word tans oorheers deur die gebruik van 'n meganiese damp-kompressiesisteem wat 'n verkoeler as medium gebruik om die kwaliteit van voedsel op 'n voorgeskrewe standaard te behou. Globale verwarmingsisteem-verkoelers word egter nie hiervoor aangewend nie. Hitte-energie bewaringsisteme met faseveranderingsmateriaal (FVM) fokus op latente hitteberging en kan 'n opsie wees om die omgewingsimpak wat met kweekhuis-gasvrystellings geassosieer word, te beperk (Anisur et al., 2013). Suid-Afrika is verbind tot die uitfasering van die gebruik van verkoelers wat die osoonlaag benadeel, soos ooreengekom in die Montreal Protokol Ooreenkoms (Programme, 2016). Die styging in kweekhuisgasvrystellings is die groot dryfkrag agter die ontwikkeling van hernubare energiebronne (Sharma et al., 2009). Om faseveranderingsmateriaal suksesvol te gebruik, moét so 'n sisteem op dieselfde standaard as die konvensionele meganiese damp-kompressiesisteme funksioneer. Faseveranderingsmateriale met latente hitte-energieberging moet aan drie fundamentele vereistes voldoen: lading (bevriesing); die stoor van hitte-energie; en ontlading (ontdooiing) (Fernandes et al., 2012; Dincer en Rosen, 2011). Wanneer verskillende toepassings vergelyk word en energieverbruik, kweekhuis-gasvrystellings en die koste oorweeg word, is die ontwikkeling van volhoubare energiebronne met termiese energiebewaring met Thermal Energy Storage Systems (TESS) 'n belowende alternatief vir verkoelingsvervoer. Die gebruik van FVMe kan tot $40 \%$ besparing teweegbring in kweekhuisgasse wat vrygestel word tydens die gebruik van die damp-kompressie verkoelingsisteem wat aangedryf word deur 'n dieselmasjien (Tassou et al., 2009). Die tradisionele damp-kompressieverkoelingsisteem het 'n hoë geraasvlak tydens gebruik as gevolg van die bewegende dele, en vereis omvattende onderhoud van die verkoelingsisteem. Die gebruik van 'n eutektiese sisteem met latente hittebewaringsmateriaal verskil van tradisionele verkoelingsisteme deurdat ' $n$ koue bron deur die storingsmateriaal voorsien word- die eutektiese sisteem is stil en betroubaar en verskaf vinnige verkoeling vir ' $n$ bepaalde tyd (Tassou et al., 2012). Tydens 'n ontleding van huidige literatuur beskikbaar rakende grootskaalse faseveranderingsmateriaal is dit duidelik dat min navorsing gedoen is rakende die gebruik in verkoelingsvervoer van lae-temperatuurtoepassings (Anisur et al., 2013).

Die meerderheid van termiese energiebewaringsmateriale word gebruik in bouverwante toepassings, sonkragberging, sonkragkookmiddels en vir kweekhuistoepassings (Anisur et al., 2013). Daar is verskillende toepassingsareas waar FVMe aangewend word. Aanvanklike aanwending van FVMe sluit die koue berging in spoorweg- en trokvervoer in waartydens eutektiese plate wat met FVM gevul is en water, ys en eutektiese sout as die stoormateriaal gebruik is. FVMe is reeds in die 1800's deur die Britse spoorweë gebruik om sitplekke gedurende die winter te verwarm. Natriumtiosulfaatpentahidraat met 'n smeltpunt en vriespunt van $44.4^{\circ} \mathrm{C}$ is in rubbersakke geplaas wat as 'n stoormedium aangewend is (Dincer en Rosen, 2011).

In landelike gebiede van Suid Afrika waar daar geen toegang tot krag (of die elektrisiteitsraamwerk) bestaan nie, kan faseveranderingsmateriaal aangewend word om die temperatuur van gevriesde voedselprodukte te behou nadat dit vanaf die stedelike areas met verkoelde voertuie vervoer is. Suid Afrika is bowendien blootgestel aan kragonderbrekings as gevolg van hoë elektrisiteitsverbruik, en hier kan faseveranderingsmateriaal ook gebruik word om voedsel tydens kragonderbrekings te bewaar. Oró et al. (2012b) het die gebruik van FVMe vir die bewaring van voedselprodukte in huishoudelike yskaste ondersoek ten einde die werking van 'n nie-verkoelde voertuig tydens kragonderbrekings en vervoer te bepaal, en het bevind dat die gevriesde produkte se temperature konstant gebly het wanneer FVMe gebruik is. Warm klimaatstoestande in Suid Afrika en lang afstande tussen plase en stede vereis effektiewe en innoverende verkoelingsisteme tydens vervoer om voedselbederf te voorkom. In beide kort- en langafstandvoervoer tussen stede en plase kan die gebruik van FVMe as innoverende metode aangewend word om die produkte vars te hou en boonop bydra tot die vermindering van kweekhuisgasvrystellings. Hoewel die meeste FVMe hoë latente smeltwarmte het, is die reikwydte van hierdie smelttemperature nie geskik om die kwaliteit van bevrore voedsel in vervoerverkoeling te behou nie. Hierdie oorsig beklemtoon die behoefte om verbeterde termo-fisiese faseveranderingsmateriaal en eienskappe te ontwikkel wat in verkoelingsvervoer en -berging gebruik kan word.

\section{Faseveranderingsmateriaal}

Wanneer 'n materiaal van vaste stof na vloeistof verander, absorbeer dit hittte-energie, en wanneer dit van vloeistof na vaste stof verander, stel dit hitte-energie vry. Die faseveranderingsproses word gebruik om termiese energie in FVMe te stoor (Dincer en Rosen, 2011). Die klassifikasie van FVMe beïnvloed waar die materiaal aangewend sal word, en die houer- of bergingsmateriaal wat gebruik sal word, om termiese energiebewaring tydens die lading en ontladering te verseker. Die verskillende klassifikasies van die FVMe en bergingsgeometrie wat gewoonlik gebruik word, word hieronder aangedui. 


\section{FVM-klassifikasie}

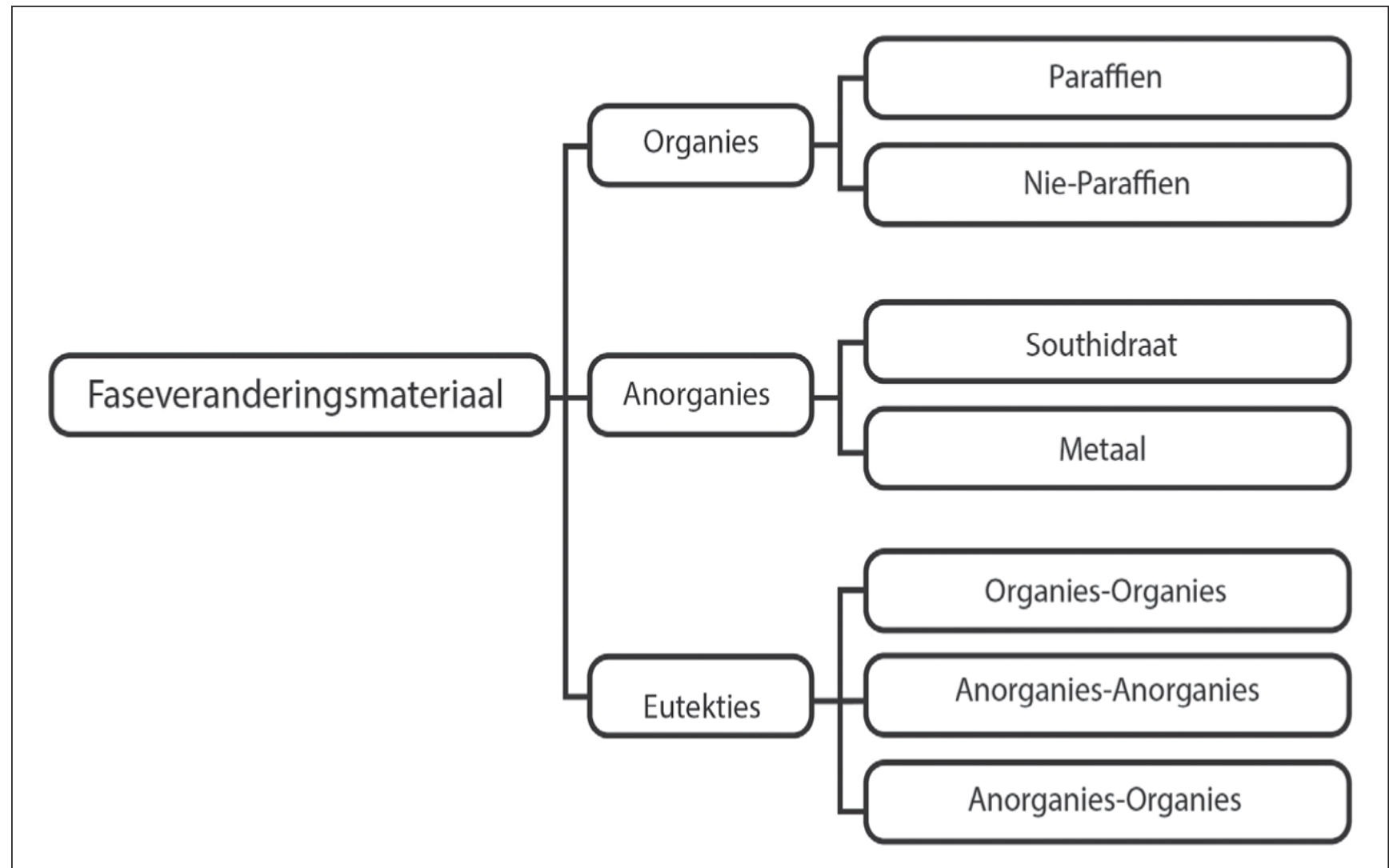

FIGUUR 1: Klassifikasie van FVMe (Abhat, 1983)

\section{a) Organies}

Organiese materiaal met sy gepaardgaande eutektiese mengsels is suksesvol gebruik in talle kommersiële toepassings soos die voedselbedryf, ruimteverhitting in geboue, verkoeling van elektroniese implemente, verkoeling en lugverkoeling (Xu et al., 2015). Hierdie organiese materiaal het ' $n$ lae termiese geleiding, wat op sy beurt ' $n$ groot hitte-oordrag-area vereis (Alva et al., 2017; Xu et al., 2015). Organiese materiaal word as paraffien en nieparaffien geklassifiseer. Hierdie materiale besit hoë smeltvries-siklusse sonder fase-segregasie en degradering van die smeltwarmte van die materiaal.

\section{- Paraffien}

Paraffienwas word wyd aangewend, omdat dit goedkoop is met redelike termiese stoordigtheid. Sisteme wat paraffien gebruik word beskou as prosesse met lang vriessmelt-siklusse (Sharma et al., 2009). Paraffienwas en suiwer paraffien het steeds beter eienskappe na 1000 tot 2000-smeltvries-siklusse (Alva et al., 2017). Die voordeel van die gebruik van paraffien is dat die smelttemperatuur en latente smeltwarmte toeneem met'n verhoging in koolfstofatome binne sekere perke (Zalba et al., 2003). Ongewenste eienskappe sluit in:

(i) baie lae termiese geleiding,

(ii) onversoenbaarheid met plastiese houers, en

(ii) middelmatige vlambaarheid.

\section{- Nie-paraffien}

Nie-paraffien bestaan uit 'n groot verskeidenheid van materiale wat as faseveranderingberging aangewend kan word. Die voordele hiervan bo paraffien met dieselfde eienskappe is dat hul hul eie eienskappe besit tydens 'n variasie in temperatuur. Vetsure is organiese verbindings met smeltwarmte van dieselfde reikwydte as paraffien. Vetsure is ook bekend vir reproduseerbare smelting en bevriesingsiklusse; hulle benodig min of geen superverkoeling nie, maar die nadeel is die koste wat hoër is as dié van paraffien, soms twee tot twee en 'n half keer meer as paraffien (Sharma et al., 2009).

Vetsure is vir die gebruik in sonverwarming- en verhittingstoepassings ondersoek (Sarı en Kaygusuz, 2001). Tabel I beskryf geselekteerde paraffien en nie-paraffien faseveranderingsmateriale. Gebaseer op die smelttemperatuur kan afgelei word dat die meerderheid van FVMe bruikbaar is vir sonverhitting. Die FVMe in die opsomming het egter geen toepassing vir die bewaring van gevriesde voedselprodukte nie as gevolg van hul smelt-temperature.

Paraffien is goedkoper, veilig en roes nie. 
TABEL I: Termiese eienskappe van geselekteerde parafien en nie-parafien FVM (Abhat, 1983; Sharma etl., 2009; Sharma en Sagara, 2005).

\begin{tabular}{|c|c|c|c|c|c|}
\hline Soort & Samestelling & Smelt-temperatuur $\left({ }^{\circ} \mathrm{C}\right)$ & Smeltwarmte $(\mathrm{KJ} / \mathrm{Kg})$ & Digtheid $\left(\mathrm{Kg} / \mathrm{m}^{3}\right)$ & Warmte-geleiding (W/mK) \\
\hline \multirow[t]{5}{*}{ Paraffien } & 6106 & $42-44$ & 189 & 900 & 0.21 (solied) \\
\hline & P116 & $45-48$ & 210 & 817 & - \\
\hline & 6035 & $58-60$ & 189 & 920 & 0.21 (solied) \\
\hline & 6403 & $62-64$ & 189 & 912 & 0.21 (solied) \\
\hline & 6499 & $66-68$ & 189 & 930 & 0.21 (solied) \\
\hline \multirow[t]{5}{*}{ Nie-paraffien } & Mieresuur & 7.8 & 247 & 1226.7 & - \\
\hline & Gliserien & 17.9 & 198.7 & 1260 & - \\
\hline & $\mathrm{D}$ - melksuur & 26 & 184 & 1249 & - \\
\hline & Caprylone & 40 & 259 & - & - \\
\hline & Camphene & 50 & 238 & - & - \\
\hline \multirow[t]{5}{*}{ Vetsure } & Maagsuur & 32 & 152.7 & $878(\mathrm{l}), 1004(\mathrm{~s})$ & 0.153 \\
\hline & Lauriensuur & 44 & 177.4 & $862(\mathrm{l}), 1007$ (s) & 0.147 \\
\hline & Steariensuur & 69 & 202.5 & $848(\mathrm{I}), 965$ (s) & 0.172 \\
\hline & Palmitiensuur & 64 & 185.4 & 850 (l), 989 (s) & 0.162 \\
\hline & Myristiese suur & 58 & 186.6 & 861 (I), 990 (s) & \\
\hline
\end{tabular}

\section{b) Anorganies}

Anorganiese materiaal word ook as southidraat en metaal gekategoriseer. Dié materiaal is nie geneig tot superverkoeling en degradering van die smeltwarmte tydens termiese siklusse nie. Daar bestaan wel bepaalde southidrate wat vanaf die vloeistofstaat voor kristallisering super-verkoelas gevolgvanswakkernvormingseienskappe, maar 'n kernvormingsagent kan bygevoeg word om te help met kristallisering. Southidrate besit 'n hoë latente smeltwarmte en hoë termiese geleiding maar die nadeel is inkongruente smelting wat plaasvind wanneer die sout nie heeltemal oplosbaar in water by die smeltpunt is nie (Sharma et al., 2009). Metallurgiese FVMe word nie gebruik nie as gevolg van gewigsbeperkings, maar die voordele is dat dit 'n hoë termiese geleibaarheid en hoë smeltwarmte per volume-eenheid het (Sharma et al., 2009). Tabel II is 'n opsomming van verskeie anorganiese FVMe wat gebruik kan word.

\section{c) Eutektiese materiaal}

'n Eutektiese materiaal is ' $n$ kombinasie van twee of meer materiale en word as organiese en anorganiese samestellings geklassifiseer. Die eutektiese materiaal vries en smelt sonder segregasie of skeiding, en stel termiese energie vry by 'n konstante temperatuur (Oró et al., 2012a). 'n Waterige oplossing, southidrate, sout en water word ook as eutektiese mengsels beskou. Tabel III dui die FVMe aan wat in die bewaring van gevriesde produkte gebruik kan word.
Soos gesien kan word in Tabel III, is die meerderheid van die FVMe eutektiese soutwateroplossings. Die smelt- en vriestemperature van water is by $0{ }^{\circ} \mathrm{C}$. Die vriespunt van water kan onderdruk word deur sout by te voeg. Soos wat sout by die water gevoeg word, word die vriespunt van die water verlaag totdat dit 'n eutektiese punt van die soutwateroplossing bereik (Li et al., 2013). By hierdie spesifieke eutektiese punt smelt en vries die soutwater by dieselfde temperature. Soutwateroplossings word egter verkies as gevolg van hul hoë latente smeltwarmte- en temperature. Om 'n variasie in die die smelttemperatuur te bewerk, moet die soutkwaliteit in 'n soutwater-gebaseerde oplossing varieer word, en dit is duidelik uit die tabel dat sub-zero temperatuur-FVMe vryelik beskikaar is as wateroplossings. Degradering by hoë termiese siklusse van hierdie soutwater-FVM beperk die toepassings en betroubaarheid daarvan, en verlies van latente hittebewaring tydens bevriesing na langdurige gebruik van die FVM is gewoonlik die gevolg (Cantor, 1979).

\section{FVM houer - eutektiese plate}

Die FVM houers word gevul met die FVM oplossing in 'n vloeistof fase en dan gevries tot die verlangde temperatuur, wat afhanklik is van die FVM wat gebruik word, bereik is. Die toepassing van die latente hitteberging (LHB) word beperk deur die onvoldoende stabiliteit tussen die bergingmateriaal en die houer. Dit is as gevolg van roes wat ontstaan tussen die houer en die FVM materiaal, en die swak

TABEL II: Geselekteerde FVM (da Cunha en Eames, 2016; Abhat, 1983; Sharma et al., 2009).

\begin{tabular}{|c|c|c|c|c|c|}
\hline Tipe & Samestelling & Smelttemperatuur $\left({ }^{\circ} \mathrm{C}\right)$ & Smeltwarmte (KJ/Kg) & Digtheid $\left(\mathrm{Kg} / \mathrm{m}^{3}\right)$ & Warmte-geleiding (W/mK) \\
\hline Sout-hidrate & $\begin{array}{c}\text { Water } \\
\mathrm{KF} \cdot 4 \mathrm{H}_{2} \mathrm{O} \\
\mathrm{CaCl} 2 \cdot 6 \mathrm{H}_{2} \mathrm{O} \\
\mathrm{Na}_{2} \mathrm{SO}_{4} \cdot 10 \mathrm{H}_{2} \mathrm{O} \\
\mathrm{Ba}(\mathrm{OH})_{2} \cdot 8 \mathrm{H}_{2} \mathrm{O} \\
\end{array}$ & $\begin{array}{c}0 \\
18.5 \\
29.7 \\
32.4 \\
78 \\
\end{array}$ & $\begin{array}{l}333 \\
231 \\
171 \\
254 \\
267\end{array}$ & $\begin{array}{c}920 \\
1447 \text { by } 20^{\circ} \mathrm{C} \\
1710 \text { by } 25^{\circ} \mathrm{C} \\
1485(\mathrm{~s}) \\
2180(\mathrm{~s})\end{array}$ & $\begin{array}{c}1.60(\mathrm{~s}), 0.61(\mathrm{I}) \\
- \\
- \\
0.544 \\
1.17(\mathrm{~s}) \\
\end{array}$ \\
\hline Metale & $\begin{array}{l}\text { Gallium } \\
\text { Cerrolow eutektikum } \\
\text { Bi-Cd-In eutektikum } \\
\text { Cerrobend eutektikum } \\
\text { Bi-Pb-In eutektikum }\end{array}$ & $\begin{array}{l}30 \\
58 \\
61 \\
70 \\
70\end{array}$ & $\begin{array}{c}80.3 \\
90.9 \\
25 \\
32.6 \\
29\end{array}$ & $\begin{array}{l}- \\
- \\
- \\
- \\
-\end{array}$ & $\begin{array}{l}- \\
- \\
- \\
- \\
-\end{array}$ \\
\hline
\end{tabular}


TABEL III: Eienskappe van lae temperatuur-FVMe (Abhat, 1983; Sharma et al., 2009; Liu et al., 2012, Oró et al., 2012b; Li et al., 2013).

\begin{tabular}{|c|c|c|c|c|c|}
\hline Soort & Samestelling & Smelt-temperatuur $\left({ }^{\circ} \mathrm{C}\right)$ & Smeltwarmte (KJ/Kg) & Digtheid $\left(\mathrm{Kg} / \mathrm{m}^{3}\right)$ & Warmte-geleiding (W/mK) \\
\hline Eutektiese soutwater & $\mathrm{NaBr}(40.3$ wt. $\%)+\mathrm{H} 2 \mathrm{O}$ & -28 & 175.69 & - & - \\
\hline Eutektiese soutwater & $\mathrm{NaCl}(22.14$ wt.\%) + $\mathrm{H} 2 \mathrm{O}$ & -21.2 & 222 & $1165(\mathrm{~s}), 1108(\mathrm{I})$ & - \\
\hline Eutektiese soutwater & $\mathrm{NaNO}_{3}+\mathrm{H}_{2} \mathrm{O}+$ toevoegings & -18 & 306 & 1300 & $0.5-0.7$ \\
\hline Eutektiese soutwater & $\mathrm{NaNO}_{3}\left(36.9\right.$ wt.\%) $+\mathrm{H}_{2} \mathrm{O}$ & -17.7 & 187.79 & - & - \\
\hline Eutektiese soutwater & $\mathrm{NH}_{4} \mathrm{NO}_{3}\left(41.2\right.$ wt.\%) $+\mathrm{H}_{2} \mathrm{O}$ & -17.35 & 186.29 & - & - \\
\hline Eutektiese soutwater & $\mathrm{Ca}\left(\mathrm{NO}_{3}\right)_{2}(35 \mathrm{wt} . \%)+\mathrm{H}_{2} \mathrm{O}$ & -16 & 199.35 & - & - \\
\hline Eutektiese soutwater & $\mathrm{NH}_{4} \mathrm{Cl}\left(19.5\right.$ wt.\%) $+\mathrm{H}_{2} \mathrm{O}$ & -16 & 248.44 & - & - \\
\hline Eutekties & Dietileen glikol & -10 & 247 & $1200(\mathrm{I})$ & - \\
\hline Eutekties organies & $\begin{array}{l}\text { Tridecane (40 wt.\%) + } \\
\text { Dodecane (60 wt.\%) }\end{array}$ & -9.7 & 159 & - & - \\
\hline Organies & n-Dodecane & -9.6 & 216 & - & $2.21(\mathrm{I})$ \\
\hline Eutektiese soutwater & $\mathrm{BaCl}_{2}(22.5$ wt. $\%)+\mathrm{H}_{2} \mathrm{O}$ & -7.8 & 246.44 & - & - \\
\hline Organies & Trietileen glikol & -7 & 247 & $1200(\mathrm{I})$ & - \\
\hline Eutektiese organies & $\begin{array}{c}\text { Tridecane (80 wt.\%) + } \\
\text { Dodecane (20 wt.\%) }\end{array}$ & -5.4 & 126 & - & - \\
\hline Organies & n-Tridecane & -5.3 & 154.5 & 756 (I) & - \\
\hline Eutektiek organies & Tetradecane + octadecane & -4.02 & 227.52 & - & - \\
\hline Eutektiese soutwater & $\mathrm{KNO}_{3}\left(9.7\right.$ wt.\%) $+\mathrm{H}_{2} \mathrm{O}$ & -2.8 & 296.02 & - & - \\
\hline Water & $\mathrm{H}_{2} \mathrm{O}$ & 0 & 333 & $920(\mathrm{~s})$ & $1.6(\mathrm{~s}), 0.61(\mathrm{I})$ \\
\hline
\end{tabular}

stabiliteit van die FVM se eienskappe weens termiese siklusse (Zalba et al, 2003). Wanneer die uitleg van die eutektiese plate in verkoelingsvoertuie oorweeg word, is die uitleg nie geoptimeer nie aangesien die plate gewoonlik teen die bokant van 'n dak gemonteer word, wat aanleiding gee tot nie-uniforme temperatuurverspreiding, wat op sy beurt weer kan lei tot die kwaliteitsverlies van die inhoud van die houer. Die eutektiese plate wat gevul is met FVM het swak termo-fisiese eienskappe, en sonder die optimering van die uitleg van die plate kan dit die oorsaak wees waarom daar min ontwikkelling was vir die gebruik van LBH in verkoelingsvervoer. Optimering van die eutektiese plate se uitleg moet verseker dat daar 'n uniforme temperatuurverspreiding in die vrag van die voertuig is. Dit is duidelik vanuit gepubliseerde literatuur dat die mees algemene vorms van die houers reghoekig, skulp, buisvormig of silindries is (Agyenim et al, 2010). Na die vereisde FVM termo-fisiese eienskappe bereik is, het die houermateriaal wat gebruik word 'n direkte impak op die hitteoordrag van die stelsel (Agyenimm et al, 2010). Oppervlakteinvreting en degradering van die houermateriaal besmet die FVM oplossings wat lei tot ' $n$ verlies aan FVM termiese bergingskapasiteit. Wanneer die bergingskapasiteit verminder word, sal dit die behoud van gevriesde produkte direk beïnvloed gedurende verkoeling aangesien daar lae hitte-oordrag sal wees tussen die produkte en die houeroppervlakte. Ferrer et al (2015) en Oró (2013) het die korrosie tussen FVMe en die metaalhouers ondersoek en gevind dat koper en koolstaal hoë roestempos het wanneer dit gebruik word as FVM houers. Die langtermyn gebruik van 'n FVM en houermateriaal vereis 'n deeglike keuse uitoefening, aangesien versuim om dit te doen die prestasie van die hittebergingsisteem kan beïnvloed.

Wanneer 'n latente hittebergingsmateriaal smelt, is daar 'n soliede vloeistofkoppelvlak teenwoordig wat aanhoudend wegbeweeg vanaf die houeroppervlak (hitte-oordragoppervlak). Dit verminder die hittevloed as gevolg van 'n toename in termiese weerstand wat veroorsaak word deur die toenemende laag van die soliede vloeistofkoppelvlak (Cabeza et al., 2002). Ander tegnieke vir die verbetering van hitte-oordrag behels die byvoeging van die metaalmatrys in die FVM. Cabeza et al. (2002) het die gebruik van vlekvrye staal, koper en grafietmatrys as hitte-oordragmateriale met water as die FVM getoets. Die hoogste hitteoordrag was met die gebruik van koper en grafiekmatrys waargeneem, met grafietmatrys wat die hoogste hitteverdragstempo gehad het. Oró et al. (2012b) was suksesvol met die gebruik van 'n vlekvrye-staalhouer om die FVM te verkan, en twee verskillende FVMe met die latente smeltwarmte van 306 en $233 \mathrm{KJ} / \mathrm{Kg}$ is gebruik met 'n smelttemperatuur van onderskeidelik -18 en $-21.3^{\circ} \mathrm{C}$. Die FVMe is gebruik om bevrore voedsel by 'n lae temperatuur te hou. Die FVM-houer was binne 'n vertikale vrieskas of vrieshok toe die elektriese toevoer vir 12 tot 24 uur afgeskakel is, en daar is bevind dat die gebruik van FVM grootliks daartoe bygedra het dat die lae temperatuur behou kon word sonder die gebruik van enige verkoelingsisteem (Oró et al., 2012b). Hierdie studie van die gebruik van FVM met geen bykomende verkoelingsisteem nie, bewys dat die vervoer van bevrore produkte suksesvol uitgevoer kan word met geen afname of skade aan die kwaliteit van die vervoerde produkte nie. Gin en Farid (2010) het aluminium as FVM-houer aangewend. Die aluminiumplate was teen drie kante van die binnekantste wande van 'n vertikale vrieskas gebruik. 'n Eutektiese samestelling van ammoniumchloried en water is as FVM aangewend, en die navorsers het bevind dat die gebruik van FVM om bevrore voedsel by lae temperature te bewaar die kwaliteit van die bevrore produkte suksesvol behou het. 


\section{Kriteria vir die keuring van FVM}

Daar is kriteria waaraan voldoen moet word om die suksesvolle toepassing van latente hittebergings-materiaal te verseker. Tabel $1 \mathrm{~V}$ dui belangrike karakterkenmerke van faseveranderingsmateriaal aan wat oorweeg moet word vir die onderskeie gebiede van toepassing. Selfs al toon sekere faseveranderingsmateriale swak eienskappe, kan dit steeds aangepas word om aan die behoefte van die toepassings te voldoen. Verder kan bepaalde faseverandermingsmateriaal met swak stoorkwaliteite verbeter word om aan die behoeftes van die aanwending te voldoen deur die byvoeging van nano-deeltjies om die termiese geleiding van die spesifiekeFVM te bevorder (Pielichowska and Pielichowski, 2014).

TABEL IV: Opsomming van die vereistes van FVM (Anisur et al., 2013; Oró et al., 2012a).

\begin{tabular}{l|l}
\hline \multicolumn{1}{c|}{ Eienskappe } & \\
\hline Termiese-fisieke eienskappe & Hoë latente smeltwarmte \\
\hline & Hoë termiese geleiding in vaste stowwe en vloeistowwe verhoog die termiese lading en ontslagkoers \\
\cline { 2 - 2 } & Hoë digtheid maak voorsiening vir hoë energiebewaringsdigtheid en vereis dus 'n klein volumehouer vir die sisteem \\
\cline { 2 - 2 } & 'n Toepaslike vries-smelttemperatuur is wenslik \\
\cline { 2 - 2 } & Hoë termiese siklusse \\
\hline Kernvorming en kristalgroei & Hoë kristalgroei om die energievereistes te fasiliteer tydens die hitteherstelling \\
\hline Chemiese eienskappe & Hoë kernvormingtempo is noodsaaklik om te verseker dat die ontdooiing en vriesprosesse by dieselfde temperatuur \\
\hline & plaasvind. \\
\hline Ekonomie & Geen roes van die omsluitingsmateriaal nie \\
\hline & Nie-toksies en nie-plofbaar \\
\cline { 2 - 2 } & Geen degradring van material word verlang na die vries-ontdooiingsiklus nie \\
\hline & Koste-effektief en bekostigbaar \\
\hline
\end{tabular}

\section{Termiese eienskappe benodig}

\section{- Latente warmte}

Wanneer ' $n$ materiaal ' $n$ faseverandering van vaste stof tot vloeistof ondergaan, absorbeer dit hitte-energie, en wanneer dit verander van vloeistof na vaste stof, stel dit hitteenergie vry. 'n Faseveranderingsmateriaal wat faseoorgang deurloop, is 'n latente hittebewaringsmateriaal (LHB). Hierdie faseveranderingsproses word gebruik om termiese energie in FVMe te stoor (Dincer and Rosen, 2011). Die gebruik van faseveranderingsmateriaal in lae temperatuurtoepassings vereis die gebruik van latente hittebewaringsmateriaal. Die voordele van sodanige materiaal is hul hoë energiebewaringsdigtheid per volume-eenheid per massa-eenheid en die materiale stoor hitte-energie by ' $n$ konstante temperatuur, wat ooreenstem met die ontdooiingstermperatuur van die FVM (Sharma and Sagara, 2005). Die latente hitte-energie wat deur 'n FVM vrygestel word gedurende die ontdooing van 'n vaste stof tot 'n vloeistof is die eienskap wat nuttig is om voedselprodukte by hul vereiste temperatuur te bewaar. Hoe hoër die latente hitteenergie wat 'n FVM kan stoor, hoe kleiner die volume van die FVM wat benodig word. Hoë latente hitte-energie is dus verkieslik.

\section{- Smelt-temperatuur}

Die smeltingstermperatuur van 'n FVM bepaal die gebied van toepassing. Daar is verskillende faseveranderingsmateriale met hul eie unieke smeltemperature: 'n FVM met 'n sub-zero smelttemperatuur kan gebruik word vir die bewaring van gevriesde voedsel; 'n FVM van $0^{\circ} \mathrm{C}$ tot $18^{\circ} \mathrm{C}$ kan gebruik word vir voedselverkoeling en 'n FVM met 'n smelt-temperatuur van $18^{\circ} \mathrm{C}$ tot $25^{\circ} \mathrm{C}$ kan in lugverkoeling aangewend word. Ander toepassings waar die smelttem- peratuur van FVM gebruik kan word, is die verkoeling van elektroniese toestelle, die motorbedryf vir masjienverkoeling, ruimteverwarming en -verkoeling, en die voedselindustrie ten einde die styging in voedseltemperature te verminder (Pielichowska and Pielichowski, 2014).

- Warmtegeleivermoë

'n FVM se vermoë om termiese hitte te gelei is uiters belangrik tydens die gebruik van latente hittemateriaal. Lae termiese geleiding in 'n FVM beperk effektiewe gebruik van gestoorde termiese energie. Om die gebruik van die latente hitte-energie te verhoog, moét die termiese geleiding van die FVM verhoog word (Li, 2013). 'n FVM met hoë termiese geleiding kan hitte-energie maklik absorbeer en vrystel.

\section{Die bepaling van termiese eienskappe van fase- veranderingsmateriaal}

Faseveranderingsmateriaal is betroubaar wanneer dit chemies, termies en fisiek stabiel bly na herhaalde termiese siklusse. As gevolg van langtermyn gebruik, kan die eienskappe van die faseveranderingsmateriaal degradeer en agteruitgang is nie wenslik vir enige faseveranderingsmateriaal nie. Zalba et al. (2003) het 'n oorsig van faseveranderingsmateriaal van verskillende oorspronge gedoen, en hulle het bevind dat daar tans groot teenstrydighede in die beskikbare literatuur met verwysing na die latente hitte- en smeltingstemperature bestaan. Daar is dus ongetwyfeld 'n behoefte om die termo-fisiese eienskappe van beskikbare faseveranderingsmateriale voor gebruik daarvan te evalueer, en dit kan gedoen word by wyse van herhaalde termiese siklusse in die laboratorium (Rathod en Banerjee, 2013). Deur bepaling van die ontdooi- 
ing en vries-eienskappe van die faseverandering se LHB, kan toepassing oor 'n lang termyn verseker word (Abhat, 1983). Daar is bestaande maatstawwe om die termiese siklusse, ontdooiing en vrieseienskappe van FVMe te meet. Dit is krities belangrik om die latente warmte van die subzero temperatuur FVMe by wyse van 'n akkurate tegniek wat die korrekte fase-oorgang kan meet, te ontleed. Die verskillende tegnieke wat gebruik word, kan as volg opgesom word:

\section{Differensiële Skandeerkalorimetrie (DSK)}

Differensiële skandeerkalorimetrie is die mees algemene laboratoriumtegniek om die smeltwarmte en smeltingstemperature van 'n FVM te meet. Die DSK meet die hoeveelheid hitte-energie wat vereis word om die temperature van ' $n$ monster en 'n verwysingsmateriaal as ' $n$ funksie van temperatuur te verhoog (Rathod en Banerjee, 2013). Die monster en die verwysingsmateriaal word beide verhit en verkoel in afsonderlike oonde (soos in Fig II gesien kan word). Die resultate van die differensiële skandeerkalorimetrie word in Energie-Tyddiagramme (termografie) aangedui en slegs ' $n$ klein hoeveelheid van die monster hoef getoets te word. Dis is duidelik uit die beskikbare literatuur dat talle outeurs van die DSK gebruik maak om die smelt- en vriesvlakke van FVM te bepaal.

Die DSK slaag egter nie daarin om betekenisvolle resultate ten opsigte van die vriespunt en graad van superverkoeling vir southidraat FVMe te lewer nie (dus nie geskik om FVMe te toets wat superkoud is nie (Abhat, 1983). 'n Eksperimentele opstelling wat 'n termostatiese waterbad gebruik soos in Fig III gesien kan word, word deur talle navorsers gebruik om die super-verkoelingseffek van soutkoolhidrate en eutektiese soutwateroplossings te bepaal (Yinping en $Y i$, 1999; Marín et al., 2003; Yilmaz S, 2010; Liu et al., 2015; He et al., 2012).

\section{Differensiële termiese ontleding (DTO)}

Die DTO werk op dieselfde wyse as die DSK. Die DTO verskil van die DSK daarin dat dieselfde hitte- en verkoelingsoond gebruik word soos gesien word in Fig II. Die DTO is ouer as die DSK tegniek, en 'n DTO is minder sensitief vir klein hitteveranderings as 'n DSK (Klančnik et al., 2010).

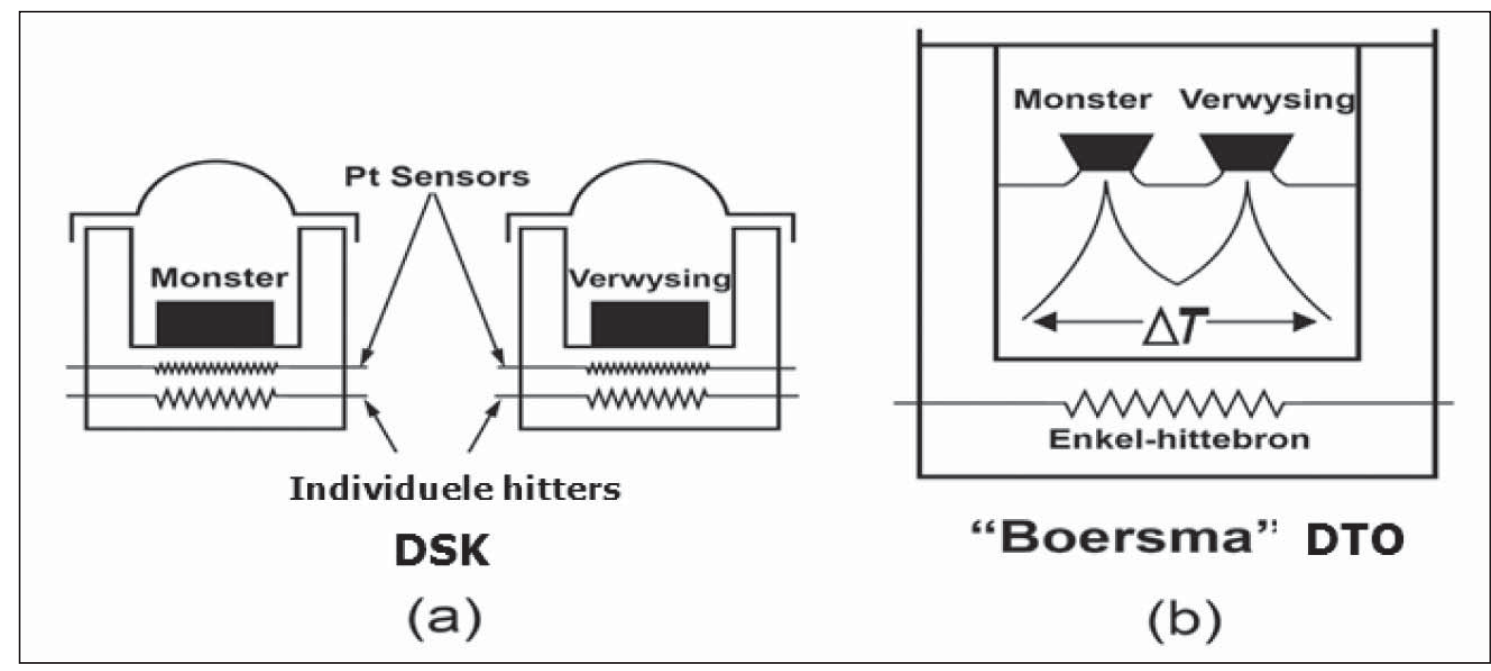

FIGUUR II: Monster en verwysingsmateriaal opstelling in 'n (a) DTO en (b) 'n DTA instrument (Klančnik et al., 2010).

\section{Temperatuurgeskiedenismetode}

Yinping en Yi (1999) het 'n temperatuurgeskiedenismetode ontwikkel om die termiese geleiding te bepaal, asook die spesifieke warmtekapasiteit, smelttemperature en die smeltwarmte tydens faseverandering. Wanneer 'n soutkoolhidraat FVM in 'n klein houer geplaas word, word die toename in superverkoeling met 'n geassosieerde afname in fase-segregasie waargeneem (Abhat, 1983). Die koste van beide DTO en DSK is hoog, en hierdie toerusting kan nie die termo-fisiese eienskappe van sekere FVMe gelyktydig meet nie (Yinping en Yi, 1999). Marín et al. (2003) het die temperatuurgeskiedenismetode verbeter deur die resultate te vergelyk met wat verkry is van DSK, en waar suiwer paraffien C16 as FVM gebruik was. Die voordeel van hierdie metode in vergelyking met DSK en DTO is dat dit ongekompliseerd en koste-effektief is. Dié tegniek maak gebruik van warm en koue waterbaddens en het die vermoë om die superverkoeling duidelik te bewys, terwyl die DSK nie 'n betekenisvolle smeltkurwe vir soutwateroplossings kan verskaf nie. 


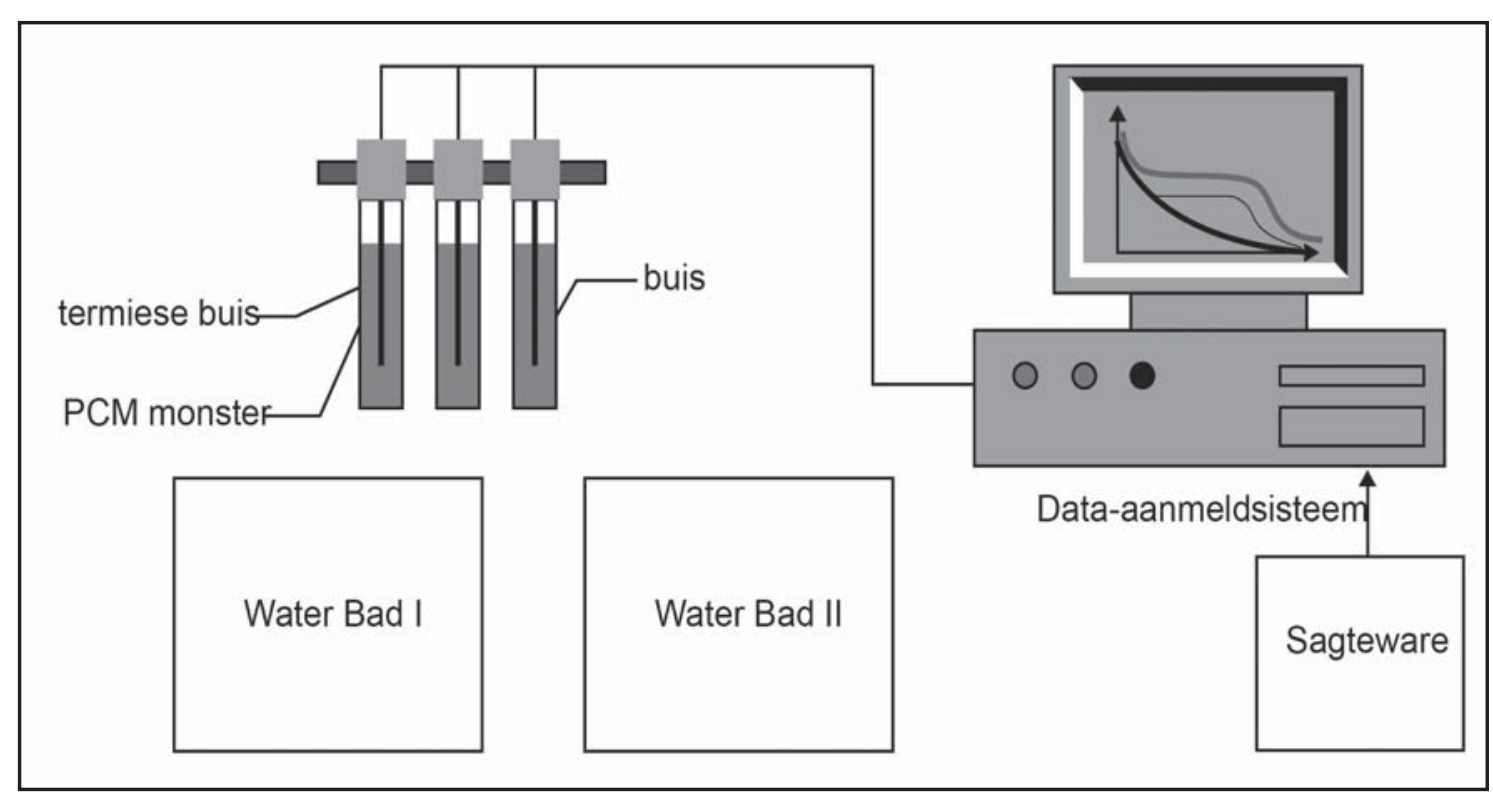

FIGUUR III: Die eksperimentele opstelling van die temperatuurgeskiedenismetode (Yinping en Yi, 1999).

Die eksperimentele resultate van suiwer paraffien C16, ontleed deur Marin et al. (2003), bewys dat die akkuraatheid van enige toetsmetode krities belangrik is. Misleidende beoordeling van die FVM se latente warmte kan 'n negatiewe impak op die toepassing in voedselbewaring vir sub-zero toestande inhou, omdat die stoorkapasiteit die gebruikstydperk bepaal. Tabel $\mathrm{V}$ toon die resultate van verskillende latente warmtes op grond van verskillende toetsmetodes op dieselfde materiaal.

TABEL V: Verskil hitte-waarde tussen 'n DSK en 'n temperatuurgeskiedenismetode (Marín et al., 2003).

\begin{tabular}{l|c}
\hline Toetsmetode & $\begin{array}{c}\text { Latente warmte } \\
(\mathbf{k J} / \mathbf{k g})\end{array}$ \\
\hline Temperatuurgeskiedenis-metode & 252.01 \\
\hline DSK & 235 \\
\hline
\end{tabular}

Die resultate in Tabel V toon dat dit krities belangrik is om die korrekte toetsmetode te kies ten einde die sub-zerotemperatuur FVMe te bestudeer, omdat die latente warmte met tot 7\% kan verskil. Sub-zero temperatuur FVMe, veral soutwater FVMe, vereis 'n temperatuurgeskiedenismetode om superverkoelingseffekte te bestudeer. Marin et al. (2003) het voorgestel dat ' $n$ verbetering in ' $n$ temperatuurgeskiedenismetode noodsaaklik is, aangesien daar probleme opgeduik het in die eksperimentele opstelling. Soutwater FVMe in Tabel III neig tot superverkoeling wat die vriesproses verleng en om die effek teen te werk, kan kernagente soos nanodeeltjies bygevoeg word. Liu et al. (2015) gebruik die temperatuurgeskiedenismetode om die superverkoeling van watergrafienoksiednanovloeistof na te vors, en die studie dui op die moontlikheid van 'n 69.1\% vermindering in superverkoeling op 'n $0^{\circ} \mathrm{C}$ smelt-temperatuur faseveranderingsmateriaal.

\section{Toepassings van FVMe in die ver- voer van termperatuursensitiewe produkte}

Daar is verskillende FVMe wat in die literatuur beskryf word, waar daar gefokus word op hitte-oordrag deur 'n FVM te inkorporeer in die isoleringsmateriaal van 'n houer. Weinig (lae) hitte-oordrag word toegelaat tussen die buitelug omgewing en die binnekant van 'n verkoelingsvoertuig ten einde energieverbruik laag te hou. Hoë hitte-oordrag deur houerwande beteken dat meer energie benodig word om produkte teen 'n bepaalde temperatuur te hou. Ahmed et al. (2010) het 'n paraffiengebaseerde FVM ingesluit in die isolering van 'n verkoelingstrok se sleepwawande. Resultate van die toets het ' $n$ verlaging in hitte-oordragtempos getoon, wat op sy beurt besoedeling deur die dieselaangedrewe verkoelsisteem getoon het, aangesien minder energie gebruik is om die sisteem te bedryf, en gevolglik ook 'n laer energie-verbruik. 'n Verlaging van $16.3 \%$ in die oordrag van hitte van die buitekant van die sleepwa na die verkoelde vragspasie is verkry deur die byvoeging van 'n FVM by die isoleringsskuim wat gebruik is in die wande van die sleepwa. 'n Eksperiment waarin 'n FVM sisteem gebruik is om 'n bepaalde termiese toestand te behou in 'n verkoelingstrok is uitgevoer deur Liu et al. (2012). Die faseveranderende termiesebergingsstelsel (FVTBS) is gelaai deur 'n verkoelingseenheid terwyl die voertuig in die pakhuis was. Die FVTBS was aan die buitekant van die vragspasie aangesien die FVM wat gebruik is, beskou is as gevaarlik onder die Europese Amptelike Instruksie 1999/45/EC. Die verkoeleenheid is slegs gekoppel wanneer die sisteem gelaai is. Die stelsel word in Figuur IV getoon.

Hierdie sisteem het 'n hitteoordragsvloeistof wat deur die pyp vanaf die FVTBS na die verkoelingseenheid gekoppel word en is binne die verkoelde spasie. Die bedryfstelsel vanhierdiesisteemisafhanklikvandieomgewingstoestande 


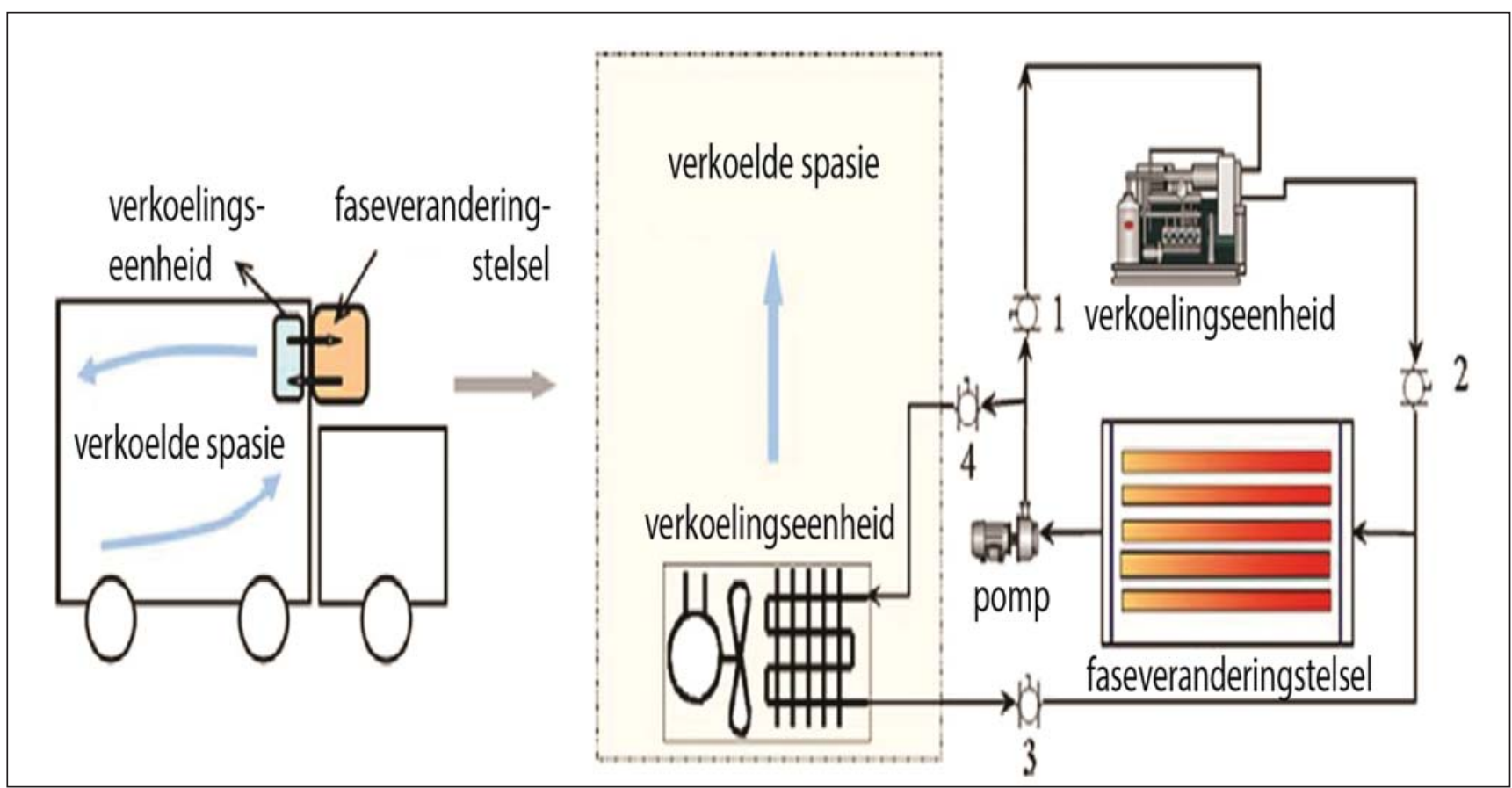

FIGUUR IV: Die opset van 'n FVM verkoelingsisteem (Liu et al., 2012).

en die verkoelingsvermoë van die FVM-houer, wat 'n nadeel is wanneer dit met tradisionele verkoelingsisteme tydens hoë omgewingstemperature vergelyk word. Die sisteem het ook 'n laer klank- of geraasvlak, laer kweekhuisgasvrystellings en verbeterde temperatuurbeheer. Volgens Liu et al. (2012) word daar egter meer navorsing benodig vir die FVM-sisteme, omdat meer materiale nog ondersoek moet word. Fioretti et al (2016) het 'n buitemuurse eksperiment vir die gebruik van 'n FVM op 'n skeepverkoeler gedoen met die doel om die verkoelingslading te verminder, en toetse was spesifiek tydens die somermaande uitgevoer. 'n Vermindering in die brandstofverbruik van die verkoelingseenheid kon bereik word omdat die FVM die hitteoordrag deur die houerwande verminder het (Fioretti et al., 2016). Tabel IV toon 'n opsomming van verskillende FVMe in die literatuur wat in verkoelingsvervoer aanwend is.

Die termies-fisieke eienskappe van FVMe wat in die literatuur vermeld is, toon die noodsaaklikheid om FVM termiesesiklusse (vries- en smelt-siklusse) en stabiliteit te verbeter. Hoe meer 'n FVM gebruik word, hoe verder verswak dit oor tyd. Faseverwarming kan op sout FVMe voorkom (sien Tabel III) by hoë termiese siklusse as gevolg van nie-kongruente smeltingsverbindings wat plaasvind wanneer daar te min water is om die sout tydens die proses te smelt. Verlies in latente hittebergingsvermoë kan as gevolg van faseskeiding voorkom. Die byvoeg van verdikkingsagente en nanodeeltjies kan faseskeiding voorkom (Xie et al., 2017). Tabel IV toon dat die FVM meestal in die isolering van wande opgeneem word om die vlakke van hitte-oordrag tussen die verkoelde voertuigwande te verminder, wat kan bydra tot die vermindering van energieverbruik. Min ontwikkellinge in die gebruik van FVMe in die eutektiese sisteem, en spesifiek die toepassing van FVMe in verkoelvervoer, is beskryf in die literatuur terwyl die ontwikkelling en toepassing in statiese eenhede omvattend is. Daar is bevind dat die meerderheid van die FVMe wat ontwikkel is, swak termiese siklusse het en nie in eutektiese stelsels vir verkoelvoertuie gebruik kan word nie. Die swak eienskappe van FVMe in vervoerverkoeling kan lei tot bederf van vervoerde voedselprodukte. 'n Hoë FVM digtheid is belangrik omdat dit hoë termiese energieberging per eenheidsvolume beteken (Farid et al, 2004). Die FVMe wat gelys is in Tabel VI het lae digtheid en lae termiese geleidingsvermoë.

Die gebruik van 'n hoë digtheid FVM in die eutektiese plate van die verkoelingstrok sal die noodsaaklikheid vir 'n

TABEL VI: Opsomming van die onderskeie FVMe wat in verkoelingsvervoer gebruik word (Liu et al., 2012; Ahmed et al., 2010; Fioretti et al., 2016).

\begin{tabular}{|c|c|c|c|c|c|}
\hline Tipe & $\begin{array}{l}\text { Smelt-tem- } \\
\text { peratuur }\left({ }^{\circ} \mathrm{C}\right)\end{array}$ & $\begin{array}{l}\text { Smelt-warmte } \\
\qquad(\mathrm{KJ} / \mathrm{Kg})\end{array}$ & $\begin{array}{c}\text { Termiese gelei- } \\
\text { dingsvermoë } \\
(\mathrm{W} / \mathrm{mK})\end{array}$ & $\begin{array}{l}\text { Digtheid } \\
\left(\mathrm{Kg} / \mathrm{m}^{3}\right)\end{array}$ & Toepassing \\
\hline Anorganiese soutwater-oplossing & -26.8 & 154.4 & - & - & $\begin{array}{l}\text { Verkoelingstrok }-86,4 \% \text { koste-vermindering in vergelyking met } \\
\text { die konvensionele sisteem is verkry }\end{array}$ \\
\hline Paraffienwas & & 7 & 156 & 0.2 & $\begin{array}{l}770 \text { Verkoelingstrok van ' } n \text { sleepwa }-16.3 \% \text { vermindering in } \\
\text { totale hitte-oordrag is verkry }\end{array}$ \\
\hline Paraffienwas & & 35 & 220 & 0.2 & $\begin{array}{l}770 \text { Skeepshouer - } 5.55 \% \text { en } 8.57 \% \text { vermindering van hitte } \\
\text { oordrag is verkry }\end{array}$ \\
\hline
\end{tabular}


groter hitteoordragoppervlak verminder. Die nadeel van die gebruik van 'n eutektiese verkoelingsisteem in 'n verkoelingsvoertuig is dat dit nie oor lang afstande kan opereer sonder herlading (of bevriesing van die stoormateriaal) nie, in vergelyking met ' $n$ meganiese dampkompressiesisteem wat 24 uur per dag opereer.

\section{Gevolgtrekking}

Die toepassing van FVM in verkoelingsvervoer benodig steeds die ontwikkeling van nuwe materiale sowel as die optimisering van eutektiese plaatuitlegte om uniforme temperatuurverspreiding in die vrag te verseker. Daar is baie literatuur wat op die toepassing van FVMe in ander gebiede as verkoelingsvervoer fokus. Met die verbetering van termofisieseeienskappevan stoormateriaal kan verkoelingsvoertuie ook in staat gestel word om vir lang afstande te ry sonder enige bederf van die bederfbare voedsel wat vervoer word. Daar is sekere FVMe wat vir verkoelingsvervoer gebruik kan word, maar die groot uitdaging is daarin geleë dat hierdie stoormateriale in nie-bewegende verkoelingseenhede gebruik word. Verkoelingsvoertuie ondervind gedurig veranderende klimaatsomstandighede en gereelde oopmaak van deure gedurende die dag, wat beide 'n impak op die kwaliteit van die vervoerde voedsel het. Meer onlangse ontwikkelings van die toepassing van FVMe in verkoelingsvervoer behels die insluiting van faseveranderingsmateriale in die wande van die voertuig om die hitte-oordrag te verminder. Daar is 'n duidelike behoefte om gebruik te maak van eutektiese plate wat met FVMe gevul is, wat beter termiese eienskappe het sodat die latente hittebergingsmateriaal as alternatiewe verkoelingsisteme in die vervoer van bederfbare voedsel kan dien.

\section{Verwysings}

Abhat A. 1983. Low temperature latent heat thermal energy storage: heat storage materials. Solar energy 30, 313-332.

Agyenim F, Hewitt N, Eames P, Smyth M. 2010. A review of materials, heat transfer and phase change problem formulation for latent heat thermal energy storage systems (LHTESS). Renewable and sustainable energy reviews 14, 615-628.

Ahmed M, Meade O, MEedina MA. 2010. Reducing heat transfer across the insulated walls of refrigerated truck trailers by the application of phase change materials. Energy Conversion and Management 51, 383-392.

Alva G, Liu L, Huang X, Fang G. 2017. Thermal energy storage materials and systems for solar energy applications. Renewable and Sustainable Energy Reviews 68 for solar energy
Deel $1,693-706$.

Anisur M, Mahfuz M, Kibria M, Saidur R, Metselaar I, Mahlia T. 2013. Curbing global warming with phase change materials for energy storage. Renewable and Sustainable Energy Reviews 18, 23-30.

Cabeza LF, Mehling H, Hiebler S, Ziegler F. 2002. Heat transfer enhancement in water when used as PCM in thermal energy storage. Applied Thermal Engineering 22, 1141-1151.

Cantor S. 1979. DSC study of melting and solidification of salt hydrates. Thermochimica Acta 33, 69-86.

Da Cunha JP, Eames P. 2016. Thermal energy storage for low and medium temperature applications using phase change materials - a review. Applied Energy 177, 227-238.

Dincer I, Rosen M. 2011. Thermal energy storage: systems and applications. WesSussex, Verenigde Koninkryk, John Wiley \& Sons.

Farid MM, Khudhair AM, Razack SAK, Al-Hallaj S. 2004. A review on phase change energy storage: materials and applications. Energy conversion and management 45, 1597-1615.

Fernandes D, Pitié F, Cáceres G, Baeyens J. 2012. Thermal energy storage: “How previous findings determine current research priorities". Energy 39, 246-257.
Ferrer G, Solé A, Barreneche C, Martorell I, Cabeza LF. 2015. Corrosion of metal containers for use in PCM energy storage. Renewable Energy 76, 465-469.

Fioretti R, Principi P, Copertaro B. 2016. A refrigerated container envelope with a PCM (Phase Change Material) layer: Experimental and theoretical investigation in a representative town in Central Italy. Energy Conversion and Management $122,131-141$

Gin B, Farid MM. 2010. The use of PCM panels to improve storage condition of frozen food. Journal of Food Engineering 100, 372-376.

He Q, Wang S, Tong M, Liu Y. 2012. Experimental study on thermophysical properties of nanofluids as phase-change material (PCM) in low temperature cool storage. Energy Conversion and Management 64, 199-205.

Klančnik G, Medved J, Mrvar P. 2010. Differential thermal analysis (DTA) and differential scanning calorimetry (DSC) as a method of material investigation. RMZ-Materials and Geoenvironment 57, 127-142.

Li G, Hwang Y, Radermacher R, Chun H-H. 2013. Review of cold storage materials for subzero applications. Energy 51, 1-17.

Li M. 2013. A nano-graphite/paraffin phase change material with high thermal conductivity. Applied Energy 106, 25-30.

Liu M, Saman W, Bruno F. 2012. Development of a novel refrigeration system fo refrigerated trucks incorporating phase change material. Applied Energy 92, refrigerated

Liu Y, Li X, Hu P, Hu G. 2015. Study on the supercooling degree and nucleation behavior of water-based graphene oxide nanofluids PCM. International Journal of Refrigeration 50, 80-86.

Marín JM, Zalva B, Cabeza LF, Mehling H. 2003. Determination of enthalpytemperature curves of phase change materials with the temperature-history method: improvement to temperature dependent properties. Measurement science and technology 14, 184

Oró E, De Gracia A, Castell A, Farid MM, Cabeza LF. 2012a. Review on phase change materials (PCMs) for cold thermal energy storage applications. Applied Energy 99, 513-533.

Oró E, Miró L, Barrenche C, Martorell I, Farid MM, Cabeza LF. 2013. Corrosion of metal and polymer containers for use in PCM cold storage. Applied energy $109,449-453$.

Oró E, Miró L, Farid MM, Cavbeza LF. 2012b. Thermal analysis of a low temperature storage unit using phase change materials without refrigeration system. International Journal of Refrigeration 35, 1709-1714.

Pielichowska K, Pielichowski K 2014. Phase change materials for thermal energy storage. Progress in Materials Science 65, 67-123.

Programme G-CS. 2016. Mitigating emissions in the transport refrigeration sector in South Africa [Aanlyn]. S.l.: Deutsche Gesellschaft für Internationale Zusammenarbeit (GIZ) GmbH. Beskikbaar by: https://www.giz.de/en/ worldwide/29177.html [Gebruik Maart 2017].

Rathod MK, Banerjee J. 2013. Thermal stability of phase change materials used in latent heat energy storage systems: A review. Renewable and Sustainable Energy Reviews 18, 246-258.

Sarı A, Kaygusuz K. 2001. Thermal performance of myristic acid as a phase change material for energy storage application. Renewable Energy, 24, 303-317.

Sharma A, Tyagi VV, Chen C, Buddhi D. 2009. Review on thermal energy storage with phase change materials and applications. Renewable and Sustainable energy reviews $13,318-345$.

Sharma SD, Sagara K. 2005. Latent heat storage materials and systems: a review. International Journal of Green Energy 2, 1-56.

TASSOU, S., DE-LILLE, G. \& GE, Y. 2009. Food transport refrigeration-Approaches to reduce energy consumption and environmental impacts of road transport. Applied Thermal Engineering, 29, 1467-1477.

Tassou S, De-Lille G, Lewis J. 2012. Food Transport Refrigeration. Centre for Energy and Built Environment Research, Brunel University, UK.

Xie N, Huang Z, Luo Z, Gao X, Fang Y, Zhang Z. 2017. Inorganic salt hydrate for thermal energy storage. Applied Sciences 7, 1317.

Xu B, Li P, Chan C. 2015. Application of phase change materials for thermal energy storage in concentrated solar thermal power plants: a review to recent developments. Applied Energy 160, 286-307.

Yilmaz SSF, Martorell I, Paksoy HO, Cabeza LF. Salt-water solutions as PCM for cooling applications. Proceedings of EuroSun 2010, international conference on solar heating, cooling and, buildings, 28 September - 1 October 2010.

Yinping Z, YI J. 1999. A simple method, the-history method, of determining the heat of fusion, specific heat and thermal conductivity of phase-change materials. Measurement Science and Technology 10, 201.

Zalba B, Mariń JM, Cabeza LF, Mehling H. 2003. Review on thermal energy storage with phase change: materials, heat transfer analysis and applications. Applied Thermal Engineering 23, 251-283. 